\title{
Effects of red reishi mushroom (Ganoderma Lucidum) on the reproductive system in female and male rats
}

\author{
B.A. Abdullah ${ }^{1 *}$, M.A. Alfahad ${ }^{2}$ and D.H. Hdree ${ }^{1}$ \\ ${ }^{1}$ Department of Pharmacology and Physiology, College of Veterinary Medicine, ${ }^{2}$ Plants Protection, College of Agriculture, \\ Tikrit university, Tikrit, Iraq, *email: pdvet10@yahoo.com
}

(Received April 23, 2018; Accepted October 28, 2018)

\begin{abstract}
The present study aimed to investigate the histological changes of Ganoderma lucidum (Red Reishi mushroom) on female and male reproductive system by using light microscope. Fifteen white rat weighing $200-250 \mathrm{~g}$ was used in the experiments. The animals was divided mainly into three groups and these groups were subdivided into 3 groups for female, and 3 groups for male, that's group represented as control group without treatment (G1). The 2nd received only $0.03 \mathrm{gm}$ and vitamin C diluted with D.W. and the 3rd group received 0.03 gm of Ganoderma lucidum. The results of the present study showed that there are no side efects of Ganoderma lucidum on female and male genital system of rats (positive effects).
\end{abstract}

Keyword: Ganoderma lucidum, Reproductive system, ovaries, testis

Available online at http://www.vetmedmosul.com

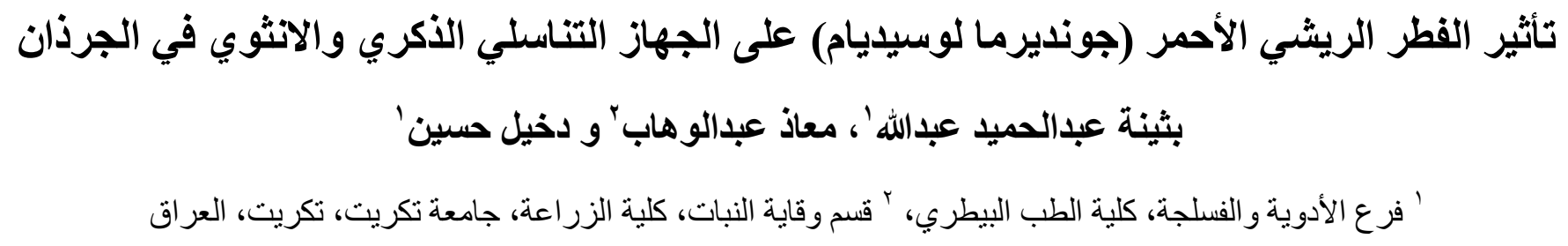

الخلاصة

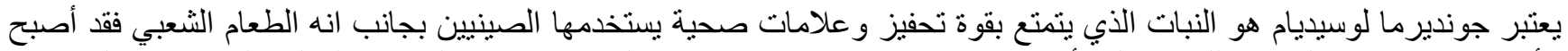

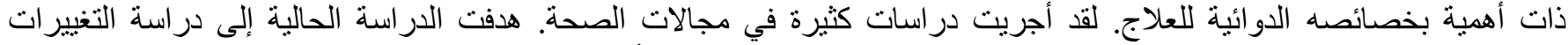

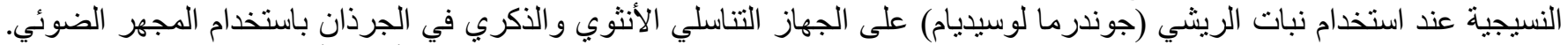

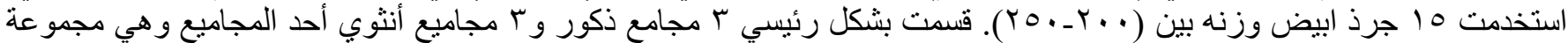

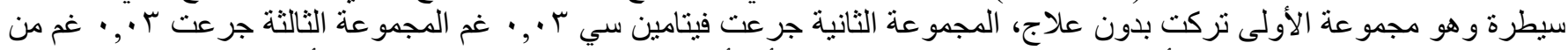
الجونيرما لوسيديام لمدة ــ بوم. أظهرت النتائج الحالية عدم وجود أي أثنار جانبية على الجهاز الذكري و الأنثوي باستخدام هذه الجرع

ومدة العلاج.

\section{Introduction}

G. lucidum is considered as a plant that have a stimulating power and it has good effect on the health, edible mashroom has importance pharmaceutical properties as well as nutritional value. Experimental studies were purposed to recognize G. lucidum effects on the health. Mushrooms are well known for their therapeutic purposes as an antibacterial, antifungal, antiviral, antitumor, immunomodulaton, antiallergic, antiatherogenic, hypoglycemic, anti-inflammatory and hepatoprotective activities $(1,2)$. These drug activites are mainly due to $\beta$ glucans, phenolics, vitamins, organic acids and trace elements $(3,4)$. The reishi mushroom grows wild on decaying logs and tree stumps in the coastal provinces of China. (5) Reishi mushrooms contain a number of active substance including specific polysaccharides. These agents are known to possess immune-modulating and anticancer properties (6), Triterpene compounds - known as ganoderic acids, which lower blood pressure, reduce platelet 
stickiness and may decrease LDLcholesterol. And, other major active compound include sterols, coumarin and mannitol. (7) Ganoderma lucidum via Krebs cycle enzymes and electron transport leads to supports mitochondrial energy production activity, and have protecting against oxidative damage. These medicinal mushrooms are commonly used for pharmaceutical purposes , such as antitumor, immunomodulating, and chronic bronchitis (8). In previous research Kayaalp (9) and Niki (10) they confirmed that "Ganoderma Lucidum a has much better effect than Vitamin C. It has a structure similar to glucose and which other six carbon monosaccharides, molecular formula of which is C6H8O6 and it is soluble in water. In humans, other primates, and guinea pigs, it is not synthesized in the body; therefore, human beings must take vitamin C with diet".

The aim of this study is evaluated the effects of of Ganoderma Lucidum on Reproductive system (female and male) in rats.

\section{Materials and methods}

\section{Animals and experimental procedure}

Fifteen female and fifteen Male Wistar rats, 6 weeks old, weighing (200-250 g) were housed under conditions of controlled temperature $\left(25 \pm 2^{\circ} \mathrm{C}\right)$ with a $12 \mathrm{~h} / 12 \mathrm{~h}$ daynight cycle in Medical Laboratory Department, College of veterinary medicine University of Tikrit. Animals supplied free access food and water ad libitum.

\section{Preparation of mushroom}

Buy it from the market (DXN) (Raeed Alkheer company) in Tikrit, type Ganoderma lucidum, vitamin C from Samara factory for medication.

\section{Experimental design}

A 15 rats were divided into 3 groups (5 rats per group). Control group (I); didn't receive any medication and gained free access to food and water and served as negative control. Vitamin C group (II) received (orally) 0.03 gm $\backslash$ day, and supplemented single dose $(0.03 \mathrm{gm})$ for 30 days. received after being diluted with distilled water (calculated the dos according to the weight of the animal).

\section{Surgical obtaining of testes epididymis and sperm retrieval}

According to the study of Colpi et al. (11) and after the treatment of the rats were anesthetically by chloroform (11) later the animals were dissected by making of inverted $\mathrm{T}$ shape in the abdominal surface there the testes each testis washed with normal slain to separate the surrounding fat and connective tissues. epididymis of each inside rat was separated dried with filter paper and was put it in a sterile saline solution, $2 \mathrm{ml}$ of phosphate buffered physiological saline (PBS, $\mathrm{pH}=7.2$ ). Suspension was pipetted and filtered through $80 \mu \mathrm{m}$ nylon mesh to remove any tissue.

\section{Semen evaluation}

\section{Sperm concentration measurement}

According to (12) the first one drop of sperm was pipetted from sperm suspension by special red blood cells pipette after well mixing to the 0.5 mark of the pipette. Then, the volume completes of with dilution solution, 200:1 and was followed by shaking to mix the suspension. In consequence, the first two drops were neglected and the third drop were placed between the cover slide and the hemocytometer chamber. The Hemocytometer was used to calculate the sperm concentration. The number of sperms were calculated in 25 small square of the corner and the center (five medium squares) (14). The number of sperms was calculated according to the known method:

\section{Percentage of sperm abnormality}

According to Ajamy et al. (13), the same slide that were utilized in calculation of live and dead sperm was applied estimate abnormality percentage under microscope with magnification power $40 \mathrm{X}$. The abnormality of the head and tail were diagnosed and the percentage of sperm abnormality was calculated according to the following formula:

Percentage of sperm abnormality $=$ No. of abnormal sperm/ total sperm No. $\times 100$.

\section{Histopathological examination}

According about to Bancroft and Gamble (14), the animals were sacrificed post month for the withdrawal of supplemented of vitamin $\mathrm{C}$ and mushroom, one cubic centimeter from testis and ovary were taken and were fixed in $10 \%$ buffered formalin, dehydrated in ascending concentrations of ethanol and cleared in xylene with final embedding in paraffin. Sections of $(5 \mu \mathrm{m})$ were prepared from each tissue block and stained with hematoxylin-eosin stain (H\&E) for mentioned histological examinations.

\section{Results}

\section{Control group}

The microscopic finding of rat ovaries this group showed normal histologic structure including epithelial, follicular structures (Figure 1).

Figures (2 and 3) showed ovary of experimental animal received vitamin C (II group). The cortex of the ovary was covered by dense connective tissue with germinal epithelium which was present on the surface of this capsule (Figure 2). showed ovary containing the primordial oocytes and was covered with simple squamous epithelium (Figure $3)$. 


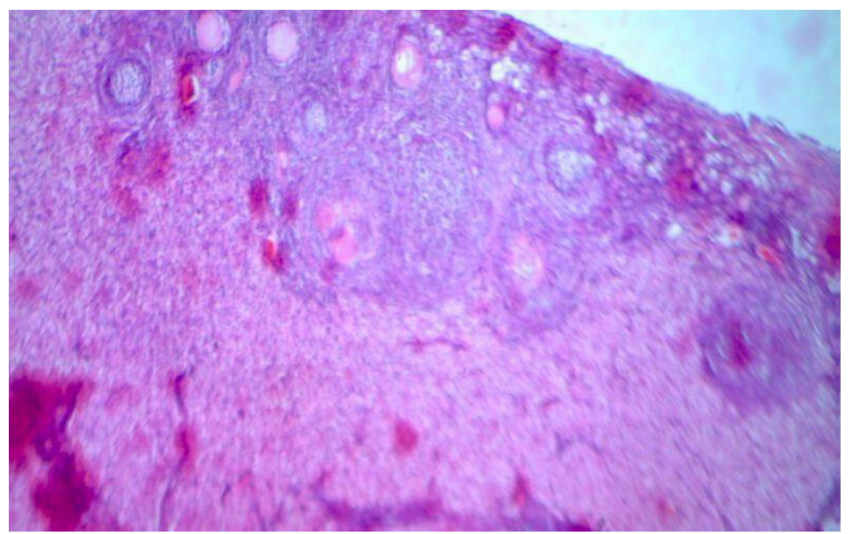

Figure 1: Microscopic picture of ovary of control group (H\&E, X40).

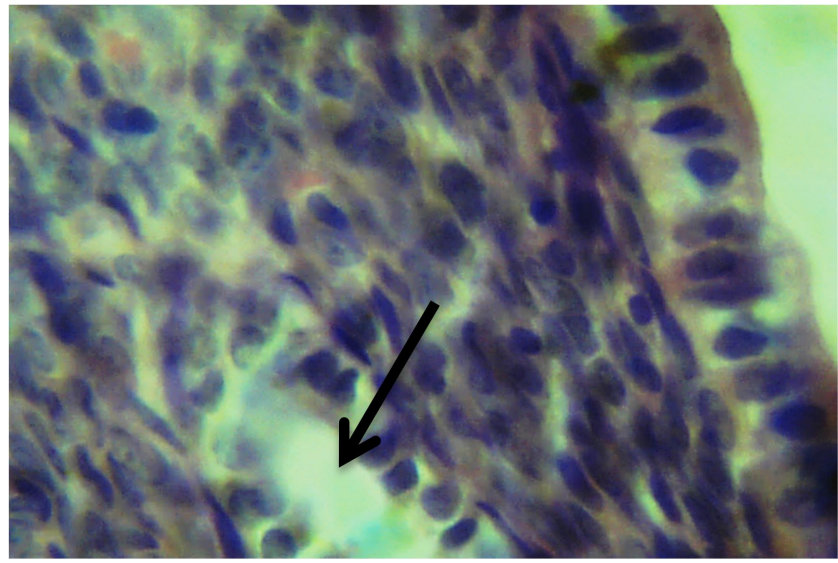

Figure 2: Microscopic pictures ovary of experimental animals received vitamin C (II group) the arrow showed primary follicle (H\&E, X40).

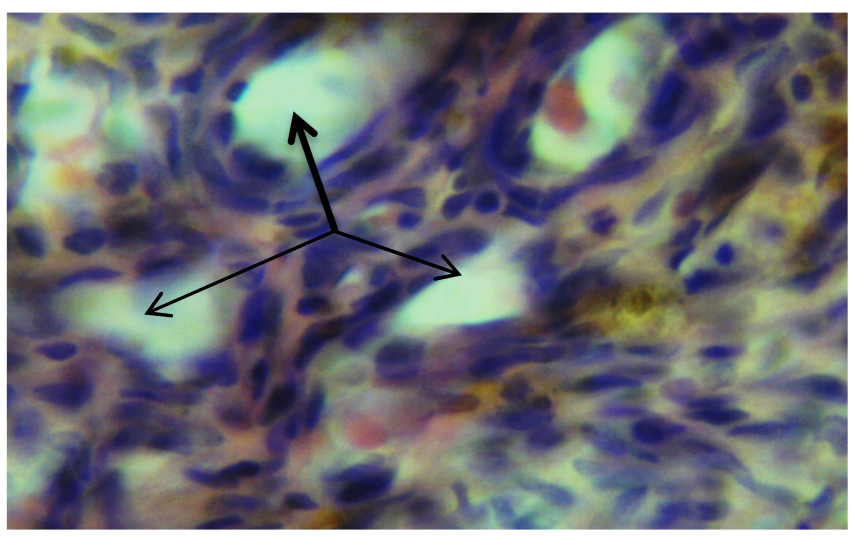

Figure 3: Histopathological changes ovary of experimental animals receive vitamin C (II group) arrow showed primary follicle (H\&E, X40).
(Figure 4) referred to the ovary of experimental animals receive of reishi mushroom (III group). The primary oocytes with simple were cuboidal cells covering the oocytes. The secondary oocytes also seen with two-three layers of epithelial cells the interstitial connective tissue was enriched with collagen bundle and fibroblast with present of WBC. There several congested blood vessels with red blood in between the oocytes.

The microscopic examination of rat ovaries. In control group, the ovaries were established to possess normal histologic structure including epithelium. In 2nd group received vitamin $\mathrm{C}$ follicular structures and other formations. Ovaries were found to be similar to control group considering its entire structures. Also, in Ganoderma lucidum group no histopathological findings were observed in either follicular structures or other formations of ovaries.

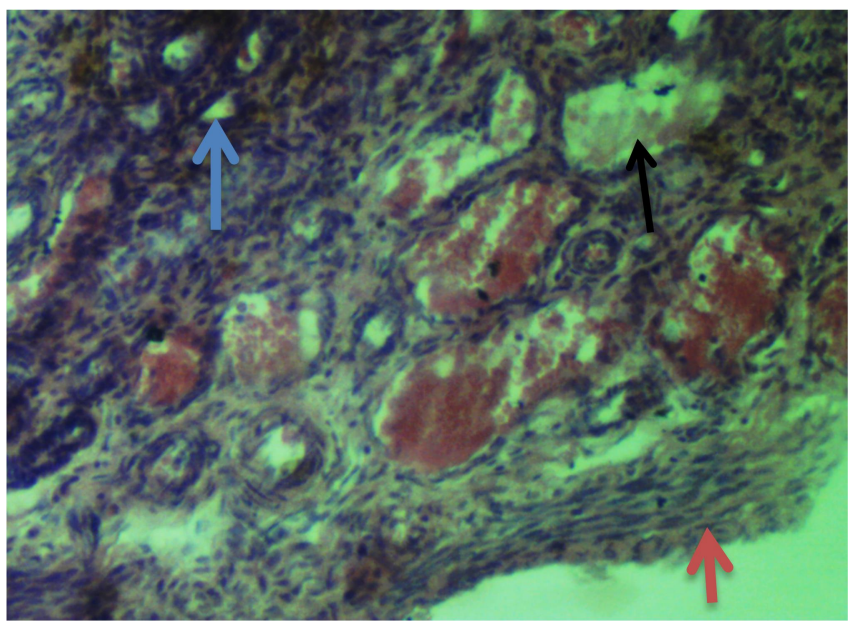

Figure 4: Histopathological changes in the ovary of experimental animal receive Reishi mushroom (Ganoderma lucidum) (III group) blue arrow showed primary follicle, the black arrow) showed the congested blood vessels, red arrow germinal epithelium of ovary (H\&E, X40).

\section{Testis}

\section{Control group}

In microscopic examination conducted on rat testes, it was observed that were established to be in normal histologic structure (Figure 5).

In microscopic examination conducted on rat testis. In control groups were observed to be in normal histologic structure. In the $2^{\text {nd }}$ group received vitamin $\mathrm{C}$ other formations. Similarly of the testis were similar to control group considering its entire structures (Figure 6). In Ganoderma lucidum group no histopathological change were observed (Figure 7). 


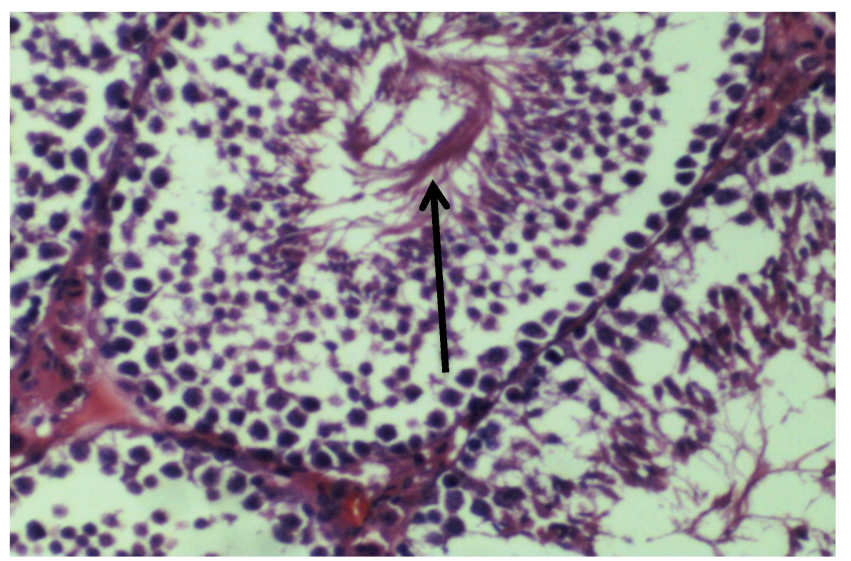

Figure 5: Histopathological picture the testis of the control group showing the spermazoa was located the center of each lumen of seminiferous tubules (SNT). The sperm were present in masses like wavy appearance, interstitial Leydig cells were present in groups and surrounded by blood capillaries. (H\&E, X40).

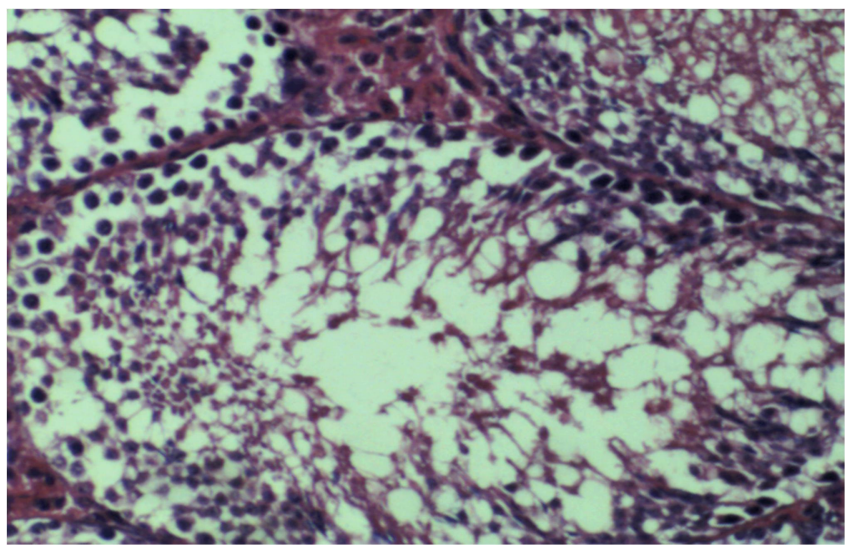

Figure 6: The histological changes of $2^{\text {nd }}$ group receiving vitamin C. the arrow showed primary follicle. Present a mass of demented spermatid mixed with remnant of sperms in the lumen of SNT also there were Leydig cells with sever atrophy in the interstitial connective tissue of testis (H\&E, $\mathrm{X} 40)$.

\section{Sperm morphology}

In the present study of the sperm morphology of the control rat compared with other groups. The results showed no significant changes in the sperms morphology in all the groups.

In the present study showed no side effect in morphology of sperm after receive Reishi mushroom (Ganoderma lucidum) (III group) and (II group) compared to the (I group) (Figure 8, 9 and 10) .also there are no significant change in normal and abnormal sperms count between groups (Table 1).

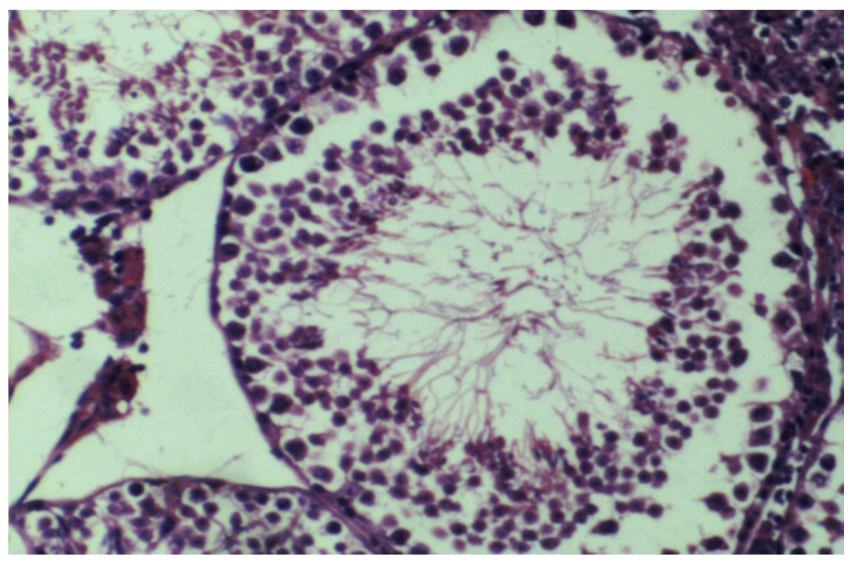

Figure 7: Microscopic picture: testes of experimental animals receive Reishi mushroom (Ganoderma lucidum) (III group) showed seminiferous tubule with different stage of spermatocytes development (arrow black). sperms content of (arrow red) and Leydig cells (blue arrow).

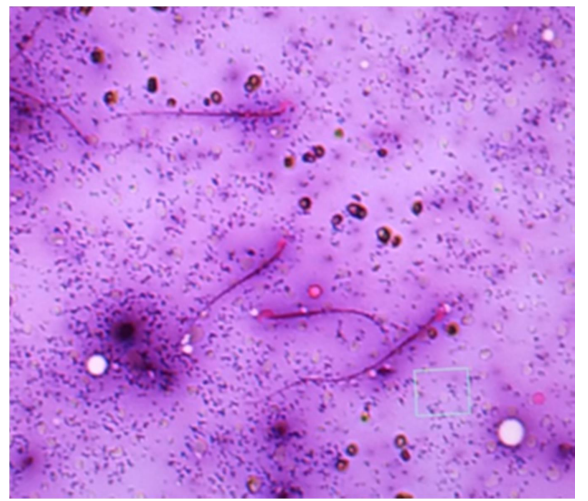

Figure 8: Microscopic picture showed the normal sperms of the control group.

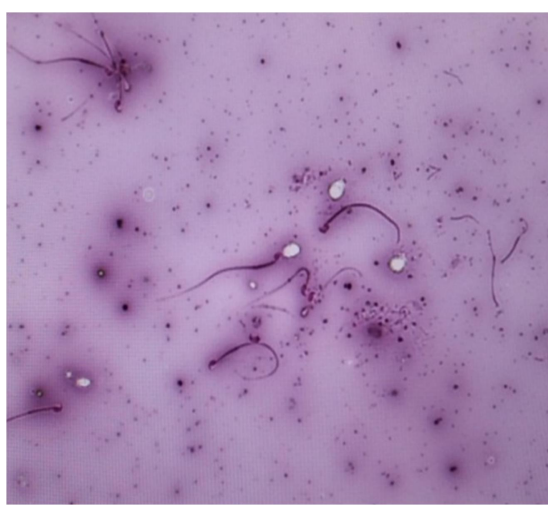

Figure 9: Microscopic picture showed sperms in the groups II received vitamin C. 


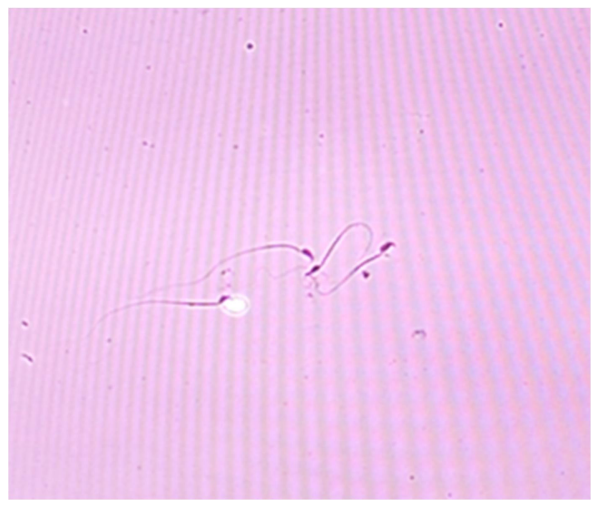

Figure 10: Microscopic picture showed the sperm in groups III received the Reishi mushroom (Ganoderma Lucidum).

Table 1: Showed no significant change in normal and abnormal sperms count $(\%)$ between groups

\begin{tabular}{lcc}
\hline \multicolumn{1}{c}{ Groups } & $\begin{array}{c}\text { Abnormal } \\
\text { sperms \% }\end{array}$ & $\begin{array}{c}\text { Normal } \\
\text { sperms \% }\end{array}$ \\
\hline Control 1 $^{\text {st }}$ group & $9.100 \pm 2.577$ & $91.200 \pm 3.200$ \\
Vitamin C 2 ${ }^{\text {nd }}$ group & $12.200 \pm 2.300$ & $84.800 \pm 2.200$ \\
Red Rieshi $3^{\text {rd }}$ group & $11.600 \pm 1.691$ & $88.400 \pm 2.582$ \\
\hline
\end{tabular}

\section{Discussion}

One of the most notable practical foods for human is mushrooms. They have been composed and cultured for hundreds of years in Asian state, like China and Japan. They have a long history of use for their health promotion benefits (15). In novel years many studies were carried out on the chemistry, the nutritional and functional characters mushroom. In present study revealed there's no negative effect of Ganoderma lucidum on female and male genital system, on ovary and testis. Similar studies proved our finding (16). Mentioned that, cultivated mushrooms are a good source of several vitamins, such as riboflavin, niacin, and folates, with concentrations, the vitamin B2 content in mushrooms is higher than that generally found in vegetables, and in some varieties even have a level as that found in egg and cheese. Also confirmed (17), mushrooms contain moderately high amounts of folates at concentrations that are of the same magnitude as is generally found in vegetables. Furthermore, the bioavailability of folates is as good as that for folic acids, also previous studies indicated the pharmacological and physiological properties of mushrooms and their impact on the increase of immunity, cure and prevention of various diseases and their roles in the improvement from life threatening diseases (18).

\section{Reference}

1. Ferreira ICFR, Vaz JA, Vasconcelos MH, Martins A. Compounds from wild mushrooms with antitumor potential. Anti-cancer Agents in Medical Chem. 2010;10:424-436.

2. Lindequist U, Niedermeyer THJ, Julich WD. The pharmacological potential of mushrooms. eCAM.2005;2: 285-299.

3. Cheung LM, Cheung PCK, Ooi VEC. Antioxidant activity and total phenolics of edible mushroom extracts. Food Chem. 2003;81:249-255.

4. Iwalokun BA, Usen UA, Otunba AA, Olukoya DK. Comparative phytochemical evaluation, antimicrobial and antioxidant properties of Pleurotus ostreatus. African J Biotechnol. 2007;6(15):1732-1739.

5. Leung A, Foster S. Encyclopedia of common natural ingredients used in foods, drugs, and cosmetics, $2^{\text {nd }}$ ed. New York: John Wiley and Sons; 1996. 255-60 p.

6. Kenneth J. Reishi (Ganoderma) Longevity Herb of the Orient Townsend Letters for Doctors and Patients. J Agr Food Chem. 1992; N.112; p.1008-1012

7. Sudheesh NP, Ajith TA, Janardhanan KK. Ganoderma lucidum karst enhances activities of heart mitochondrial enzymes and respiratory chain complexes in the aged rat. Biogerontol. 2009;10(5):627-36.

8. 8-Wasser SP, Weis AL. Medicinal properties of substances occurring in higher Basidiomycetes mushrooms: current perspective (review). Int J Med Mushrooms. 1999;1:31-62.

9. Kayaalp O. Tibbi Farmakoloji,histological examination of the role of vitamin in cyclophosphamide induced testicular damage in rats. Anadolu J Sci Tech. 2018;7:220-226.

10. Niki E. Vitamin $\mathrm{C}$ as an antioxidant selected vitamins, minerals and functional consequences of maternal malnutrition. World Rev Nutr Diet. 1991;64:1-30.

11. Colpi GM, Piediferro G, Nerva F, Giacchetta D, Colpi EM, Patti E. Sperm retrieval for intra-cytoplasmatic sperm injection in nonobstructive azoospermia. Minerva Urol Nefrol. 2005;57:99-107.

12. Agarwal A, Sharma R. Automation is the key to standardized semen analysis using the automated SQA-V sperm quality analyzer. Fert Stert. 2007;87(1):1.

13. Ajam,E.K.. Alsaadi.H.A.and ALhakeem.M.K.Reproduction ,Artificial insemination and Reproducive care ; 1982:p420

14. Bancroft JD, Gamble M. Theory and Practice of Histological Technique. $5^{\text {th }}$ ed. New York: Churchill Livingstone; 2002.

15. Zhanga M, Cuia SW, Cheungb PCK, Wanga Q. Antitumor polysaccharides from mushrooms: a review on their isolation process, structural characteristics and antitumor activity. Trends Food Sci Tech. 2007;18:4-19.

16. Mattila P, Konko K, Euvola M, Pihlava J, Astola J, Vahteristo L. Contents of vitamins, mineral elements and some phenolic compound in cultivated mushrooms. J Agr Food Chem. 2001;42:2449-2453.

17. Clifford AJ, Heid MK, Peerson JM, Bills ND. Bioavailability of food folates and evaluation of food matrix effects with a rat bioassay. $\mathrm{J}$ Nutr. 1991;21:445-453.

18. Ribeiroa B, Pinhoa PG, Andradea PB, Baptistab P, Valentao P. Fatty acid composition of wild edible mushrooms species: A comparative study. Microchem J. 2009;93:29-35. 